\title{
Labyrinthe
}

18 | 2004 (2)

La Recherche dans tous ses éclats

\section{André Lemaire, Naissance du monothéisme. Point de vue d'un historien}

Isabelle de Castelbajac

\section{(2) OpenEdition}

1 Journals

Édition électronique

URL : http://journals.openedition.org/labyrinthe/210

DOI : $10.4000 /$ labyrinthe. 210

ISSN : 1950-6031

Éditeur

Hermann

Édition imprimée

Date de publication : 15 juillet 2004

Pagination : 33-36

Référence électronique

Isabelle de Castelbajac, "André Lemaire, Naissance du monothéisme. Point de vue d'un historien », Labyrinthe [En ligne], 18 | 2004 (2), mis en ligne le 20 juin 2008, consulté le 30 avril 2019. URL : http:// journals.openedition.org/labyrinthe/210; DOI : 10.4000/labyrinthe.210

Propriété intellectuelle 


\title{
Naissance du monothéisme. Point de vue d'un historien d'André LEMAIRE*
}

\author{
Isabelle DE CASTELBAJAC \\ isabelledecastelbajac@voilà.fr
}

À la question des origines du monothéisme, qui constitue un héritage de la philosophie des Lumières, seul le concours d'un historien des religions permet de répondre en évitant le piège des problématiques définies a priori. Le livre d'André Lemaire comble, à cet égard, une double lacune: il s'efforce, dans un contexte polémique, de présenter les outils dont dispose l'historien et s'essaie à la première synthèse rigoureuse sur ce thème, faisant état des dernières découvertes archéologiques, épigraphiques et exégétiques.

L'effort de définition consenti par l'auteur concerne à la fois les méthodes de l'historien des religions et les notions dont il hérite, qui sont en général étrangères au monde qu'il décrit.

Il rappelle ainsi que si différents types de sources, comme l'épigraphie, l'archéologie et les traditions historiographiques, s'imposent à lui, une méthode spécifique doit être appliquée à chacune d'elles. Le recours à la critique historiographique soulève de nombreux débats depuis une trentaine d'années, puisque aux tenants d'une analyse synchronique des textes, considérés au mépris des antiques usages rédactionnels dans leur état final d'élaboration, s'opposent ceux d'une analyse diachronique visant à distinguer, dater et identifier les auteurs. On aurait attendu de l'historien qu'il rattache les triomphes polémiques du révisionnisme - qui, appliqué à l'histoire antique d'Israël, conteste son antériorité par rapport au christianisme - aux avancées de l'analyse synchronique et littéraire des textes importée des universités américaines. C'est la raison pour laquelle il convient de faire un bon usage de l'historiographie, en s'attachant à distinguer traditions anciennes et récentes, mais aussi à reconnaître le caractère historique

\footnotetext{
* Éditions Bayard, 2003.
} 
de traditions contredites par l'Histoire ou par des idéologies d'époques postérieures. À cet égard, l'historicité des traditions madianites relatives à Moïse est confirmée non seulement par l'hostilité des textes bibliques à ce peuple, mais encore par la date reculée de sa disparition ( $\mathrm{X}^{\mathrm{e}}$ siècle av. J.-C.).

La définition des notions exigerait l'union de l'histoire et de la philosophie, et non de simples éclaircissements étymologiques. Dans un souci de rigueur, André Lemaire souligne certes l'importance de distinguer les croyances («monothéisme», «polythéisme», «hénothéisme»), des pratiques ( monolâtrie», «idolâtrie»); essentiellement monolâtre lors de son apparition, le yahwisme affirmerait progressivement un monothéisme théorique, passant ainsi du culte d'une divinité unique à la croyance en une seule divinité. Or, ces développements pourraient davantage offrir l'occasion de souligner l'ambiguïté de la définition à la fois numérique et métaphysique du monothéisme. En effet, si, d'une part, il réside dans la croyance en un dieu unique, l'essence de la religion d'Aton reste incertaine car il s'agit encore d'un dieu cosmique, celui de la lumière. Si, d'autre part, la divinité monothéiste est dite distincte du monde, alors elle désigne aussi les dieux des religions polythéistes puisque, personnifiant une force de la nature, ils agissent sur elle de l'extérieur, autrement dit la transcendent. On peut donc se demander si l'opposition au polythéisme reste pertinente pour caractériser le monothéisme.

Enfin, il est indispensable, à la suite d'André Lemaire, de distinguer les deux formes d'aniconisme qui, tour à tour, auraient caractérisé le yahwisme: l'aniconisme "matérialisé», dans lequel la divinité est représentée sous la forme d'une pierre, mais jamais d'un homme ou d'un animal, auquel s'oppose l'aniconisme «vide» qui symbolise la divinité par son seul support (comme un veau, un taureau ou des chérubins). Toutefois, cette présentation d'André Lemaire ne rend peutêtre pas suffisamment compte de la singularité de l'aniconisme d'Israël, qu'il soit matérialisé ou vide. Peut-il vraiment être considéré comme rattaché à celui qui caractérise le monde ouest-sémitique puisque certains de ces peuples, comme les Nabatéens, les Phéniciens ou les Puniques acceptent anthropomorphismes et tériomorphismes? À l'inverse, l'Égypte et l'Assyrie révèrent des dieux non représentés. L'iconoclasme ne régnerait donc qu'en Israël. Le mérisme constitué par Exode XX, 4 et interdisant toute image sculptée trouverait donc sa 


\section{Naissance du monothéisme. Point de vue d'un historien}

source dans l'impossibilité de représenter un dieu ne ressemblant à rien d'existant, ni homme ni bête. Il s'agirait moins d'une interdiction que d'une incapacité.

À l'effort de définition consenti par André Lemaire s'ajoute le courage d'effectuer une synthèse de la masse de travaux, souvent inégaux, parus sur les origines du monothéisme depuis cent cinquante ans. Sans sacrifier à la question de savoir si le monothéisme naît d'une révolution ou d'une évolution, l'auteur distingue cinq époques, qu'il est possible de réduire à trois en distinguant histoire des idées et pratiques populaires.

Les patriarches (XIX'-XVIII ${ }^{\mathrm{e}}$ siècle av. J.-C.) seraient des polythéistes, adorant concurremment un dieu El local et des dieux claniques. Leur culte, qui se prolongera jusqu'au VIII siècle avant l'ère chrétienne, serait marqué par la présence d'un sanctuaire à ciel ouvert, d'un arbre sacré, d'une stèle et d'un autel. C'est avec Moïse (XIII siècle av. J.-C.) qu'apparaît le yahwisme d'origine madianite, aniconique et monolâtre. Les premières attestations du tétragramme datent de la fin du $\mathrm{IX}^{\mathrm{e}}$ siècle (stèles de Mesha et de Tell Dan), voire du XIV ${ }^{e}$ siècle av. J.-C., sur la liste d'un temple d'Aménophis III. Yahwé fait ici figure de dieu guerrier de la montagne et de l'orage. Il n'est d'ailleurs pas sans rappeler Baal. Son culte comporte des prières (surtout des bénédictions), des sacrifices (de communion), un autel, des stèles et un buisson sacré.

Du règne de David à celui de Yéhu ( $\mathrm{X}^{\mathrm{e}}$-IX $\mathrm{I}^{\mathrm{e}}$ siècle av. J.-C.), se développe une politique d'assimilation des dieux locaux (en particulier El) à Yahwé. La monolâtrie (ou hénothéisme) s'affirme, de même que le lien particulier unissant Yahwé à Israël, comme le montre la métaphore conjugale. Avec le schisme consacrant la rupture entre les royaumes du Nord et du Sud (931), le culte de Baal connaît un renouveau, favorisé par le prestige économique et culturel des Phéniciens. Yéhu élimine le culte de Baal. À partir d'Élie, les prophètes n'auront de cesse de proclamer l'extra-territorialité de l'action de Yahwé.

La quatrième période, couvrant les règnes séparant Ezékias de Josias (VIII-VII ${ }^{\mathrm{e}}$ siècle av. J.-C.), est marquée par une politique religieuse inverse de déracinement des cultes yahwistes locaux: les sanctuaires locaux sont supprimés en faveur du temple, les arbres sacrés et les stèles disparaissent au profit d'un aniconisme désormais «vide».

Enfin l'exil babylonien (586-538 av. J.-C.) est l'occasion de l'émergence du monothéisme au sens strict, c'est-à-dire d'un mouvement de 
pensée conscient de lui-même, comme en témoigneraient différents passages du Deutéro-Isaïe (XLIII, 10-11; XLIX, 6,8).

Sans doute est-il possible de réduire à trois grands moments l'histoire de la naissance de la pensée monothéiste, dont la genèse revêtirait un caractère politique, et qu'il convient de distinguer des pratiques populaires que textes et vestiges archéologiques rattachent à l'hénothéisme tout au long du premier millénaire.

Le monde pré-yahwiste des patriarches s'apparenterait à celui que met en scène le panthéon ougaritique, découvert près de Ras Shamra, en Syrie, à partir de 1930. El, vieillard et père des dieux, détient la sagesse et arbitre le grand conflit cosmique de la vie et de la mort. Baal, jeune dieu impétueux, se sacrifie périodiquement pour les humains, combattant la mer et la mort.

Tout se passe donc comme si, à l'époque de David, Yahwé absorbait les fonctions des grands dieux cananéens, El et Baal, puisqu'il assimile les caractéristiques des dieux El locaux tout en ayant fait siennes celles de Baal à l'époque de Moïse. On constate, avec André Caquot, que la Bible le présente à la fois comme un sage, un créateur de l'univers, source de justice et un héros guerrier, maître de l'orage et du tonnerre, principe de fertilité. Or, les pages les plus anciennes de la Bible, comme les Psaumes royaux ou la première strate des Livres de Samuel, sont, selon Caquot, déjà empreintes d'une monolâtrie bien proche du monothéisme. Le Dieu unique d'Israël est de droit le maître de l'univers entier qu'il a créé. Les autres dieux lui sont soumis ou voués à la ruine. L'unicité de la divinité et l'universalisme de la volonté divine, qui sont des traits du monothéisme, émergent déjà. L'intuition monothéiste d'Israël impose à son Dieu de maintenir seul l'équilibre d'un univers jusqu'alors assuré par la collaboration de dieux contraires et, partant, explique sa complexité.

Ce que l'on pourrait appeler, dès le $\mathrm{X}^{\mathrm{e}}$ siècle, c'est-à-dire aux débuts de la rédaction de la Bible, le proto-monothéisme d'Israël, s'approfondit à la faveur des événements politiques qui président au schisme de la royauté ainsi qu'à la chute des royaumes du Nord (en 722 av. J.-C., sous les coups de l'Assyrie) et du Sud (en 586 av. J.-C., du fait des Babyloniens). Il s'impose peu à peu et poursuit son chemin dans les traditions juives postérieures, cherchant jusqu'à aujourd'hui à répondre moins à la question de l'identité divine qu'à celle des modalités de la révélation. 